\title{
Maternal Intake of Flaxseed During Lactation and Exercise Training Protect Against Salt Overload-Induced Aortic Remodeling in Adult Offspring
}

Simoni Silva-Couto, ${ }^{\circledR}$ André Manoel Correia-Santos, ${ }^{\circledR}$ Gabriela Câmara Vicente, ${ }^{\circledR}$ Caroline Luiza Codonho Castro, Vanessa de Lana Melo Barreto, ${ }^{\circledR}$ Joyce Eduarda Campos Martins, ${ }^{\circledR}$ Queila Lenzi, ${ }^{\circledR}$ Gilson Teles Boaventura, Maurício Alves Chagas ${ }^{\circledR}$

Universidade Federal Fluminense, Niterói, RJ - Brazil.

\section{Abstract}

Background: High dietary sodium intake can induce endothelial stiffness even without changes in blood pressure.

Objectives: To evaluate the effects of exercise training and chronic intake of sodium chloride solution on aortic morphology of male offspring of rat dams who consumed flaxseed during lactation.

Methods: Female rats were fed with a control diet or a flaxseed diet during lactation. At weaning, two male offspring of each rat dam were allocated into eight groups for 180 days: four groups received a control diet e four received a flaxseed diet, with /without exercise and with/without $\mathrm{NaCl}$ solution supply. Aorta was collected for histomorphometric analysis. The one-way analysis of variance was used and $\mathrm{P}$ value $<0.05$ was considered statistically significant.

Results: The chronic use of $1 \% \mathrm{NaCl}$ solution led to changes in aortic histoarchitecture in the control group: increase in aortic intima-media thickness $(10,4 \%, \mathrm{p}<0.0001)$ and reduced number of elastic lamellae $(-8,1 \%, \mathrm{p}<0.0001)$. Groups of offspring of mother that consumed flaxseed during lactation, the chronic use of $1 \% \mathrm{NaCl}$ alone did not lead to an increase in the aortic intima-media thickness. Exercise training of adult offspring increased aortic intima-media thickness $(13.3 \%, \mathrm{p}<0.0001)$, with preservation of elastic components and aortic flexibility.

Conclusion: Chronic salt overload caused adverse effects on the aorta of rats, and maternal consumption of the flaxseed diet during lactation protected against aortic remodeling. (Int J Cardiovasc Sci. 2021; 34(2):124-133)

Keywords: Metabolism/physiology; Fatty Acids,Omega-3; Rats; Exercise; Lactation; Flaxseed Diet.

\section{Introduction}

There is evidence of the association of high sodium intake with the development of chronic non-communicable diseases (NCDs). ${ }^{1}$ High dietary sodium intake can adversely affect various organs and target tissues, such as the vasculature and heart, and some studies in rodents have demonstrated impaired endothelial function in chronic sodium intake, even without changes in blood pressure. ${ }^{2-5}$

High serum sodium increases endothelial stiffness and impairs endothelium-dependent vasodilation, and small changes in serum sodium concentration can induce endothelial stiffness in a matter of minutes. Sodium reduces the size of endothelial cells and their surface area, volume, cytoskeleton, deformability and flexibility. In addition, sodium also reduces nitric oxide (NO) endothelial synthase (eNOS) and NO production and increases transforming growth factor $\beta$ (TGF- $\beta$ ), thus increasing arterial stiffness. ${ }^{6}$

Although sodium intake required to maintain homeostasis in adults is extremely low $(<500 \mathrm{mg}){ }^{2}$ the amount consumed by the world population is nearly $3,950 \mathrm{mg}$ sodium / day. ${ }^{7}$ Reduction of salt intake has been identified as one of the most cost-effective interventions to reduce the load of NCDs, with the potential to save

Mailing Address: Gabriela Vicente

Rua Mário Santos Braga, 30/5 andar. Postal Code: 24220-900, Niterói, RJ - Brazil

E-mail: gabriela_vicente_@hotmail.com 
millions of lives every year. ${ }^{1}$ Along with proper eating habits, regular exercise training has been considered one of the main mechanisms to protect against the onset and progression of predisposing risk factors to cardiovascular diseases and other NCDs. 8,9

Studies have shown that diets containing food with functional properties, such as the flaxseed, during pregnancy and lactation can induce metabolic programming in the offspring due to its interference in the hormonal system ${ }^{10}$ and the ability of omega-3, present in this oleaginous, crossing the placenta and incorporating itself into the cellular membrane, altering its properties. ${ }^{11}$ Regarding vascular health, some studies using flaxseed during pregnancy, lactation and postweaning, reported cardioprotective effect, showing decreased aortic thickness. ${ }^{12-14}$

Flaxseed is the main plant source of n-3 fatty acid and its use has become popular due to its health benefits. It is also a source of soluble and insoluble fiber, lignan and protein, and contains $41 \%$ lipids, of which $50-55 \%$ are alpha-linolenic acid (n-3) and 15-18\% linoleic acid (n-6). ${ }^{15,16}$

The study aimed to evaluate the effects of exercise training and chronic sodium intake on the aorta morphology of male offspring of rat dams fed a flaxseed flour diet during lactation.

\section{Material and Methods}

\section{Animals}

The animal protocol was approved by the Animal Ethics Committee of the Fluminense Federal University (Protocol Number CEA 882/2016), and the procedures were in accordance with the guidelines for experimentation with animals (NIH Publication №. 85-23, revised 1996). Female wistar rats ( 3 months old) from the Centre of Laboratory Animals of Fluminense Federal University were housed under a controlled temperature $\left(21 \pm 1^{\circ} \mathrm{C}\right)$, humidity ( $60 \pm 10 \%)$ and $12 \mathrm{~h}$ light / dark cycle, with free access to water and food.

\section{Experimental Design}

Initially, 24 female rats were mated with 12 males (2:1 ratio) and fed a commercial rodent chow (Nuvilab ${ }^{\circledR}$, Nuvital Ltda, Paraná, Brazil). During pregnancy, all rats were kept in individual cages. After the offspring was born, for the lactation period, the rat dams were divided into two groups ( $n=12$ per group), following the order that the female rats gave birth: the first rat to give birth was allocated into one group, the second was allocated to the other, successively. A control group (CG) was fed a control diet and filtered water, and the flaxseed group (FG) received the diet added with $25 \%$ brown flaxseed flour, and filtered water. Diets were manufactured and stored as pellets at $4{ }^{\circ} \mathrm{C}$ in agreement with the American Institute of Nutrition (AIN-93G) recommendations for rodent diets ${ }^{17}$ (Table1). A concentration of $25 \%$ of flaxseed flour in the diet ( $25 \mathrm{~g} / 100 \mathrm{~g}$ diet) would meet the recommended fiber intake. The addition of oil was not necessary, as the seed itself is a source of oil.

At weaning, two male offspring from each mother started to receive commercial rodent chow with a normal lipid and protein content (Nuvilabß, Nuvital

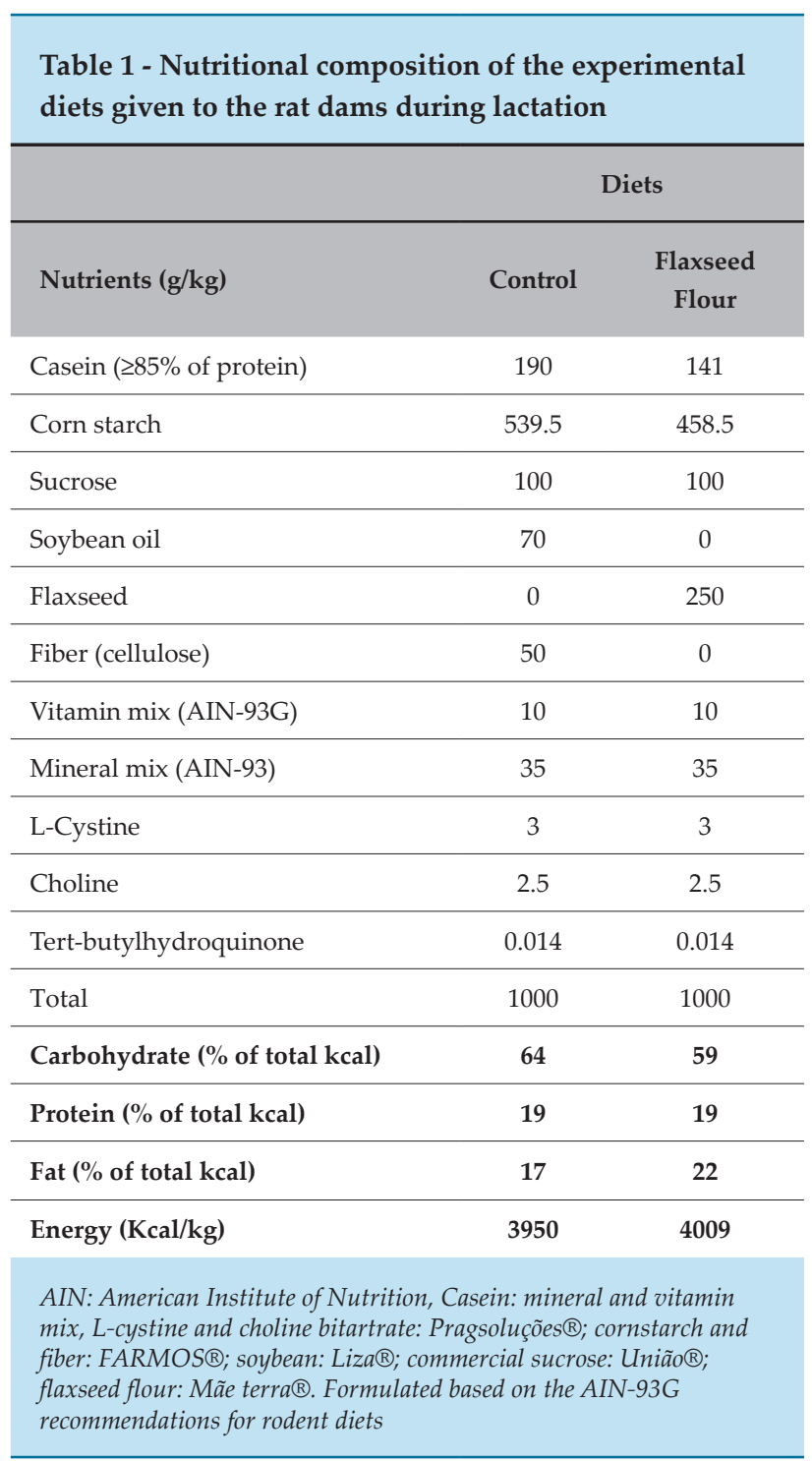


Ltda, Paraná, Brazil), containing 22\% protein (main protein sources are meat, fish, soy and amino acids), $66 \%$ carbohydrate and 11\% lipid and allocated into one of the eight experimental groups with six animals each one ( $\mathrm{n}=6)$ until they were 180 days old:

- Control group (CG), offspring of rat dams who received control diet during lactation;

- Exercise CG (ECG), offspring of rat dams who received control diet during lactation and underwent exercise training;

- Sodium chloride CG (NaClCG), offspring of rat dams who received control diet during lactation and were hydrated with $1 \% \mathrm{NaCl}$ solution;

- Exercise sodium chloride $\mathrm{CG}$ (ENaClCG), offspring of rat dams who received control diet during lactation and were hydrated with $1 \% \mathrm{NaCl}$ solution and underwent exercise training;

- Flaxseed group (FG), offspring of rat dams who received flaxseed flour diet during lactation;

- Exercise FG (EFG), offspring of rat dams who received flaxseed flour diet during lactation and underwent exercise training;

- Sodium chloride FG (NaClFG), offspring of rat dams who received flaxseed flour diet during lactation and were hydrated with $1 \% \mathrm{NaCl}$ solution; and

- Exercise sodium chloride FG (ENaClFG), offspring of rat dams who received flaxseed flour diet during lactation and were hydrated with $1 \% \mathrm{NaCl}$ solution and underwent exercise training.

The number of six animals per group followed the 3 Rs principle, which aims to reduce the number of animals used in the experiment. According to Damy et al., ${ }^{18}$ the reduced number of animals in biomedical research does not affect the detection of biological effects.

\section{Body Mass, Feed and Sodium Intake, Water and 1\% $\mathrm{NaCl}$ Solution Intake}

For analysis of body mass gain throughout the study, body mass of the groups was measured once a week on a digital scale (precision 0.01g) (Filizola®). Food intake of the groups was measured three times a week. For feed intake calculation, individual intake was obtained by subtracting the remaining feed from the amount offered. Water and $1 \% \mathrm{NaCl}$ solution intake were measured three times a week with the aid of a graduated test tube with $0.5 \mathrm{~mL}$ precision. The amount supplied and the amount remained were quantified individually to determine water and $\mathrm{NaCl}$ intake. Sodium intake calculation was made adding the sodium intake from the $1 \% \mathrm{NaCl}$ solution with the sodium contained in the commercial rat chow given to the animals (Nuvilab®, Nuvital Ltda, Paraná, Brazil) (2,700 mg Na / kg of rat chow).

\section{Exercise Training}

At 90 days of life, exercise training was performed on a motorized treadmill (AvsProjetos $\AA$, Brazil) for 12 weeks, 5 times a week for $60 \mathrm{~min}$ each session, in individual lanes. Exercise training was started at a speed of $0.3 \mathrm{~km} / \mathrm{h}$ in the first session, increasing progressively to a final speed of $1.1 \mathrm{~km} / \mathrm{h}$, according to each animal's performance. This exercise intensity corresponded to $70 \%$ to $80 \%$ of the maximum $\mathrm{VO}_{2} \cdot{ }^{19}$

\section{Blood Pressure Measurement}

When the animals were three months of age, systolic blood pressure (SBP) was measured (in $\mathrm{mmHg}$ ) once a month until six months of age, using the noninvasive method of tail-cuff plethysmography (tail plethysmograph V1.10-Insight, Brazil).

After preconditioning in a chamber, the animals were pre-heated in the chamber to $35 \pm 2^{\circ} \mathrm{C}$ for five minutes. The official SBP of each animal was calculated by averaging three consecutive stable measurements (with a difference of about one minute among them).

\section{Histomorphometric Analysis of the Aorta}

At the end of the experimental protocol (180 days), after a 6-hour fasting period, the animals were anesthetized with a solution containing $80 \mathrm{mg}$ of ketamine $(10 \%$ ketamine hydrochloride, Syntec Tecnologia Farmacêutica Aplicada à Medicina Veterinária, Brazil) and $10 \mathrm{mg}$ of xylazine ( $2 \%$ xylazine hydrochloride, Syntec Tecnologia Farmacêutica Aplicada à Medicina Veterinária, Brazil); a thoracotomy was performed and the heart and the aorta were removed. The artery was dissected from the aortic arch, and the aorta was sectioned transversely with transverse cuts in the distal end of the sections. Later, the pieces of aorta were fixed in buffered formalin at 10\% (Millonnig formalin) for 24 hours, and processed with a standard technique of paraffin inclusion, as described by Pereira et al. ${ }^{25}$ Subsequently, the paraffin blocks containing the pieces of aorta were cut using a CUT 4050 microtome (Microtec $\left.{ }^{\circledR}\right)$, in sections of $5 \mu \mathrm{m}$, stained with hematoxylin and eosin, and Weigert's Resorcin-Fuchsin for later evaluation. 
The measurements were made using the Image $₫$ software, with digital images obtained by the cellSens program with an optronics digital video camera and BX51 Olympus microscope. The images were captured at $4 \mathrm{x}$ magnification for measurement of the area, at $40 \mathrm{x}$ for analysis of thickness, and at 20x for quantification (\%) of elastic lamellae and elastic fiber. All images were digitalized in .tiff format. The aortic wall area was measured by the difference between the external and internal areas of the arterial wall. For intimamedia thickness, four different regions of the same diametrically opposite cut were analyzed for better precision. The number of lamellae was quantified in four different regions of the same cut, and the aortic elastin content (\%) was determined by analysis of Weigert's Resorcin-Fuchsin slides using the Image ${ }^{\circledR}$ software with a 20x magnification using the plugin Color Segmentation.

\section{Statistical Analysis}

Data were presented as mean \pm standard deviation. Data were tested for normality and homogeneity of variances (Kolmogorov-Smirnov test) and the differences among groups were tested, when appropriated, with one-way analysis of variance (ANOVA), followed by a Holm-Sidak post hoc test or non-parametric KruskalWallis test, followed by Dunn's post hoc test. Variables that did not present normal distribution were presented as median and interquartile range (box plot graphs). Regarding body mass and blood pressure, the two-way ANOVA test was performed, followed by the Bonferroni post hoc test. $P$ value $<0.05$ was considered statistically significant (GraphPad Prism v. 6.01 for Windows, GraphPad Software, San Diego, CA, USA).

\section{Results}

\section{Body Mass, Food Intake, Water and 1\% $\mathrm{NaCl}$ Solution Intake}

At weaning (21 days of age), no difference was found in body mass between the groups, however, there was a tendency of the offspring of the dams of the flaxseed group to be smaller than control offspring $(-16.7 \%$, $\mathrm{p}=0.0686$ ). Regarding body mass gain, it was noted that the ENaCLFG showed smaller body mass than the CG $(-14 \%, \mathrm{p}<0.05)$ and the ECG $(-14.9 \%, \mathrm{p}<0.05)$ from the $12^{\text {th }}$ week and the $16^{\text {th }}$ week, respectively, to the end of the study period. The ENaClFG also showed lower body mass than the $\mathrm{NaClCG}$ between weeks 18 and 21 $(-10.3 \%, \mathrm{p}<0.05)$ (Figure 1). Daily feed intake was not different between the groups ( $\mathrm{p}=0.1330$ ) (Table 2). During the study period, the animals receiving $1 \% \mathrm{NaCl}$ solution had a higher fluid intake than animals receiving water $(p<0.0001)$ (Table 2). Regarding daily sodium intake, the animals of the groups $\mathrm{NaClCG}, \mathrm{ENaClCG}, \mathrm{NaClFG}$ and ENaClFG consumed a higher amount of sodium than their respective groups that consumed water $(+935.5 \%$, $+845.3 \%,+833.4,+795.2 \%$, respectively, $\mathrm{p}<0.0001$ ) (Table 2 ).

\section{Systolic Blood Pressure}

Chronic consumption of $1 \% \mathrm{NaCl}$ solution did not increase blood pressure in the study groups, and neither exercise training nor the flaxseed diet affected blood pressure during the lactation period ( $\mathrm{p}=0.5016$ ) (Figure 2).

\section{Histomorphometric Analysis of the Aorta}

At the end of the study, no difference was found in aortic wall area $(\mathrm{p}=0.9364)$ or the aortic lumen area between the groups ( $\mathrm{p}=0.8817$ ) (Figures 3 and 4 ). However, the chronic use of $1 \% \mathrm{NaCl}$ solution and exercise training increased the aortic intima-media thickness in the CG $(10.4 \%$ and $13.3 \%$, respectively, $p<0,0001)$ either alone or combined $(+17.7 \%, \mathrm{p}<0.0001)$. In male offspring of female rats who consumed flaxseed during lactation, the chronic use of $1 \% \mathrm{NaCl}$ alone did not increase the aortic intima-media thickness (which was not different from the CG and the FG). Nevertheless, exercise training increased the aortic intima-media thickness in the EFG compared to the CG and FG $(12.8 \%$ and $9.7 \%$, respectively, $\mathrm{p}<0.0001)$, and the use of the $1 \% \mathrm{NaCl}$ solution combined with exercise training also increased aortic intima-media thickness when compared to CG and FG (+ $17.8 \%$ and $14.5 \%$, respectively, $\mathrm{p}<0.0001$ ) (Figures: 3 and 4 ). Regarding the elastic component of the arterial wall, the chronic use of $1 \% \mathrm{NaCl}$ solution by the CG caused a reduction in the number of elastic lamellae $(-8.1 \%, \mathrm{p}<0.0001)$, the FG showed a lower number of elastic lamellae than all CGs $(p<0,0001)$, despite that, no difference amongst the groups were observed regarding the amount of elastin in the aortic intima-media ( $p=0.1629$, Figures 3 and 4 ).

\section{Discussion}

The present study showed that maternal intake of a flaxseed diet during lactation associated with exercise 


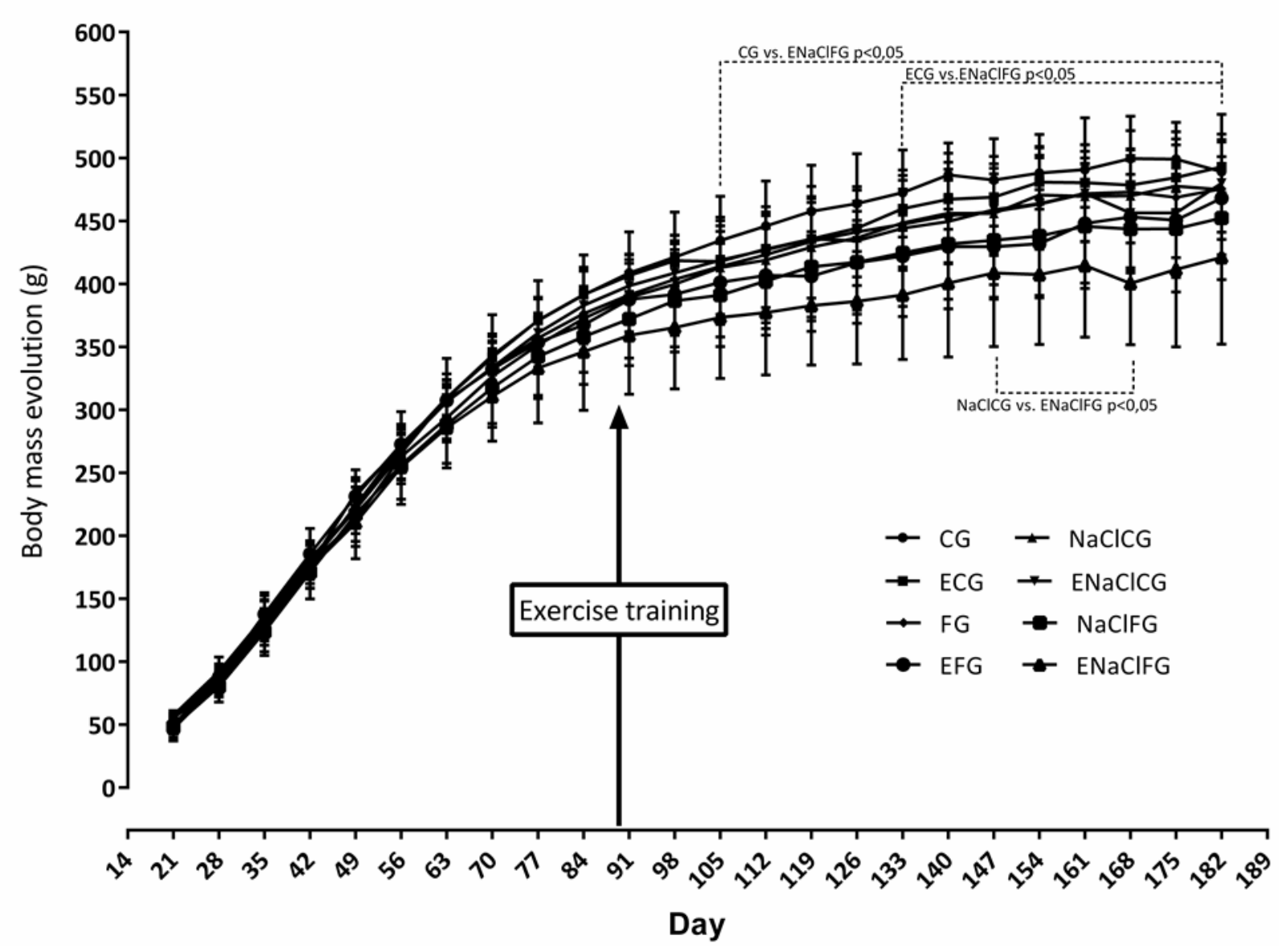

Figure 1 - Body mass evolution throughout the study. The data were presented as mean \pm SD, with significance level of $p \leq 0.05$ (twoway ANOVA, Bonferroni post-hoc test). CG: control group; NaClCG: Sodium Chloride control group; ECG: Exercise training control group; ENaClCG: Sodium Chloride exercise training control group; FG: Flaxseed group; NaClFG: Sodium Chloride flaxseed group; EFG: Exercise training flaxseed group; ENaClFG: Sodium Chloride exercise training flaxseed group.

Table 2 - Consumption of feed, water, $1 \%$ sodium chloride $(\mathrm{NaCl})$ solution and sodium $(\mathrm{Na})$

\begin{tabular}{|c|c|c|c|c|c|c|c|c|c|}
\hline $\begin{array}{l}\text { Parameters / } \\
\text { Groups }\end{array}$ & CG & $\mathrm{NaClCG}$ & ECG & ENaClCG & FG & $\mathrm{NaClFG}$ & EFG & $\mathrm{ENaClFG}$ & p-value \\
\hline Diet (g/day/animal) & $21.5 \pm 3.4$ & $22.6 \pm 1.4$ & $23.7 \pm 0.9$ & $23.2 \pm 1.6$ & $22.7 \pm 2.0$ & $22.3 \pm 1.6$ & $22.5 \pm 1.5$ & $20.5 \pm 1.5$ & 0.1330 \\
\hline $\begin{array}{l}\text { Water or } 1 \% \mathrm{NaCl} \\
\text { solution }(\mathrm{mL} / \text { day/ } \\
\text { animal) }\end{array}$ & $31.7 \pm 5.8$ & $54.0 \pm 2.6^{*}$ & $35.3 \pm 2.0^{+}$ & $54.3 \pm 6.4^{* \text {, }}$ & $33.5 \pm 4.2^{+, \S}$ & $51.2 \pm 6.9^{*,+, / /}$ & $33.2 \pm 2.9^{+, \S, \mathbb{I}}$ & 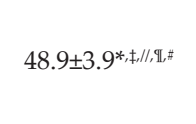 & $<0.0001$ \\
\hline $\begin{array}{l}\text { Sodium }(\mathrm{Na})(\mathrm{mg} / \\
\text { day/animal) }\end{array}$ & $58.0 \pm 9.3$ & $601.3 \pm 30.0^{*}$ & $64.1 \pm 2.5^{\dagger}$ & $606.3 \pm 69.0^{* \text {, }}$ & $61.4 \pm 5.4^{+, \S}$ & $573.1 \pm 72.7^{*, \neq, / /}$ & $60.8 \pm 4.3^{+}$, s,I & $545.1 \pm 40.7^{* \text {, 机/, }}$ & $<0.0001$ \\
\hline \multicolumn{10}{|c|}{$\begin{array}{l}\text { Data were presented as mean } \pm S D \text {, with significance level of } p<0.05 \text { (one-way ANOVA, Holm-Sidak post-hoc test). * } \neq C G ;+\neq N a C l C G ; \neq \neq E C G ; \xi \neq \\
E N a C l C G ; / / \neq F G ; \mathbb{I} \neq \mathrm{NaClFG;} \# \neq=E F G ; C G \text { : control group; NaClCG: sodium chloride control group; ECG: exercise training control group; ENaClCG: } \\
\text { sodium chloride + exercise training control group; FG: flaxseed group; NaClFG: sodium chloride flaxseed group; EFG: exercise training + flaxseed group; } \\
\text { ENaClFG: sodium chloride + exercise training + flaxseed group }\end{array}$} \\
\hline
\end{tabular}



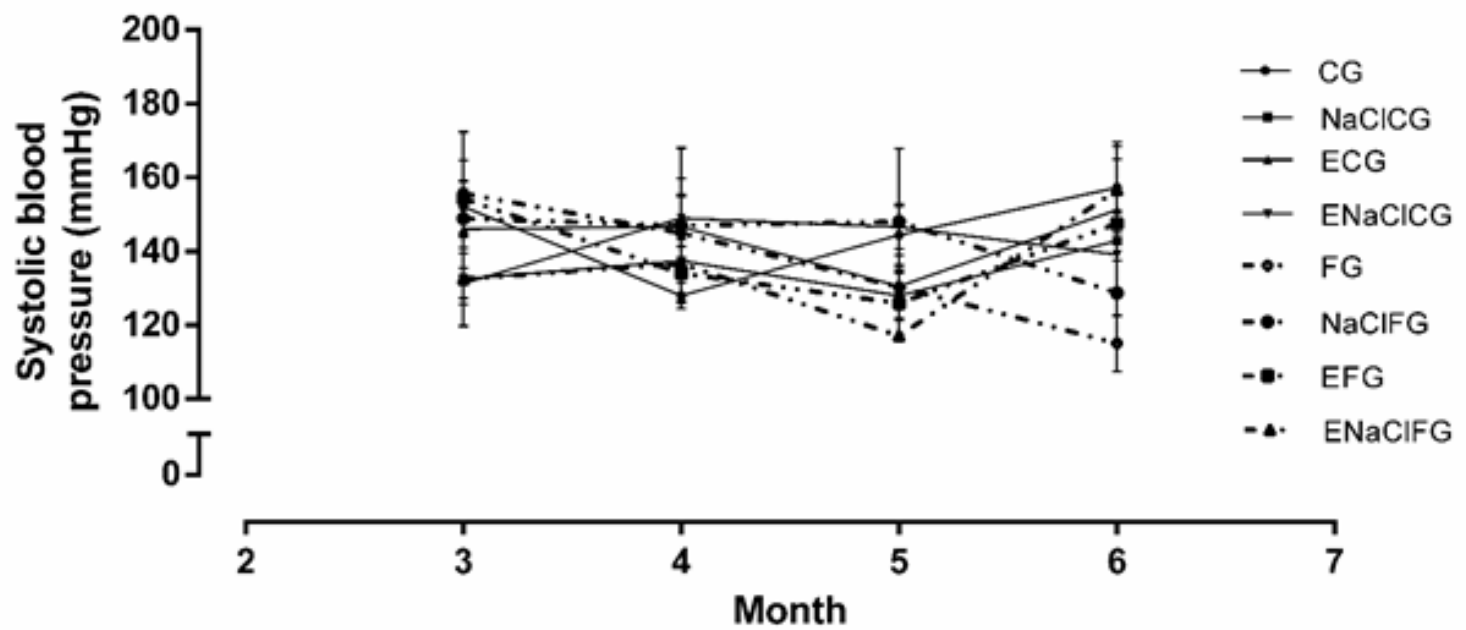

Figure 2 - Monthly systolic blood pressure of study groups. The data were presented as mean $\pm \mathrm{SD}$, with significance level of $\mathrm{p} \leq 0.05$ (two-way ANOVA, Bonferroni post-hoc test). CG: control group; NaClCG: Sodium Chloride control group; ECG: Exercise training control group; ENaClCG: Sodium Chloride exercise training control group; FG: Flaxseed group; NaClFG: Sodium Chloride flaxseed group; EFG: Exercise training flaxseed group; ENaCIFG: Sodium Chloride exercise training flaxseed group.

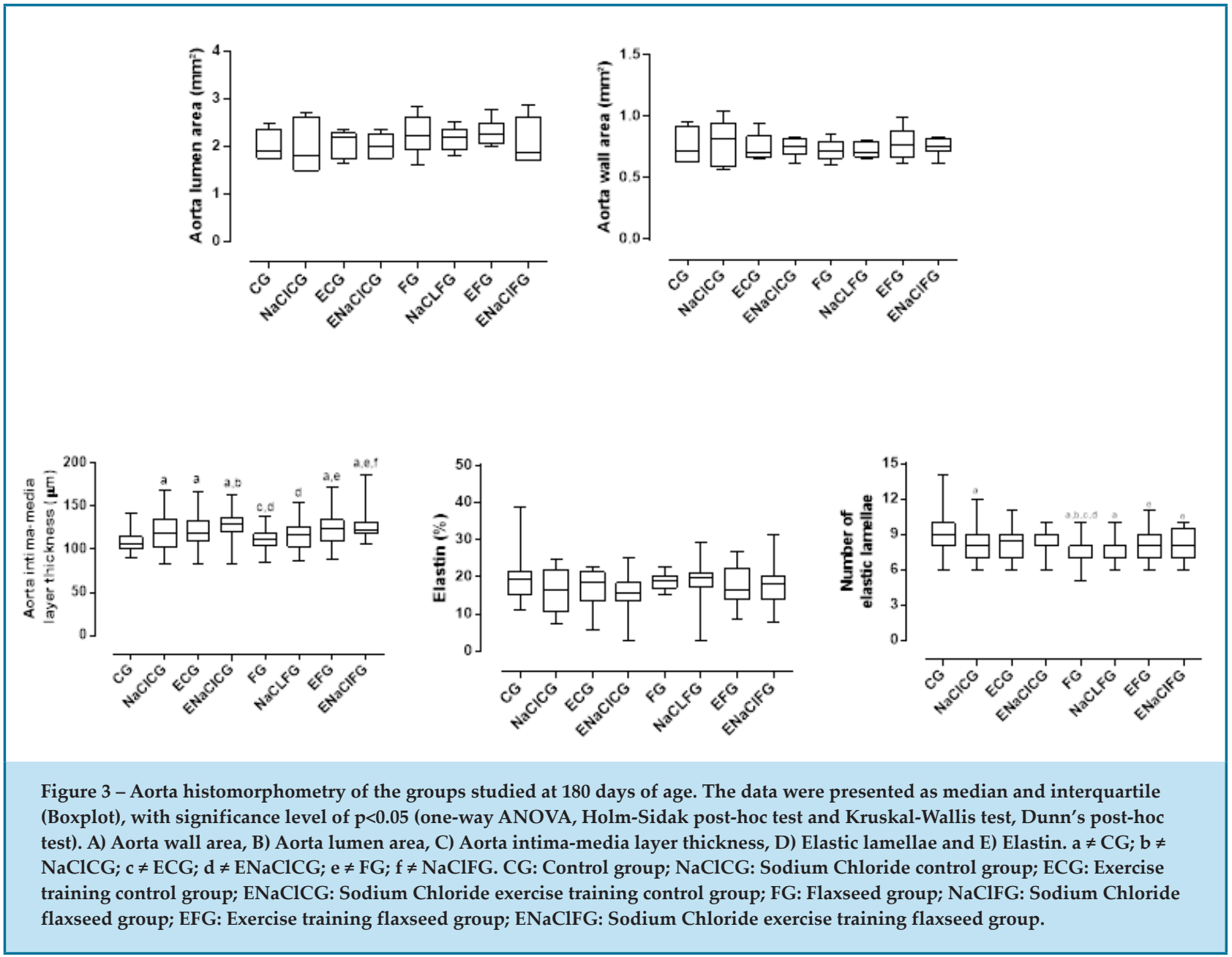




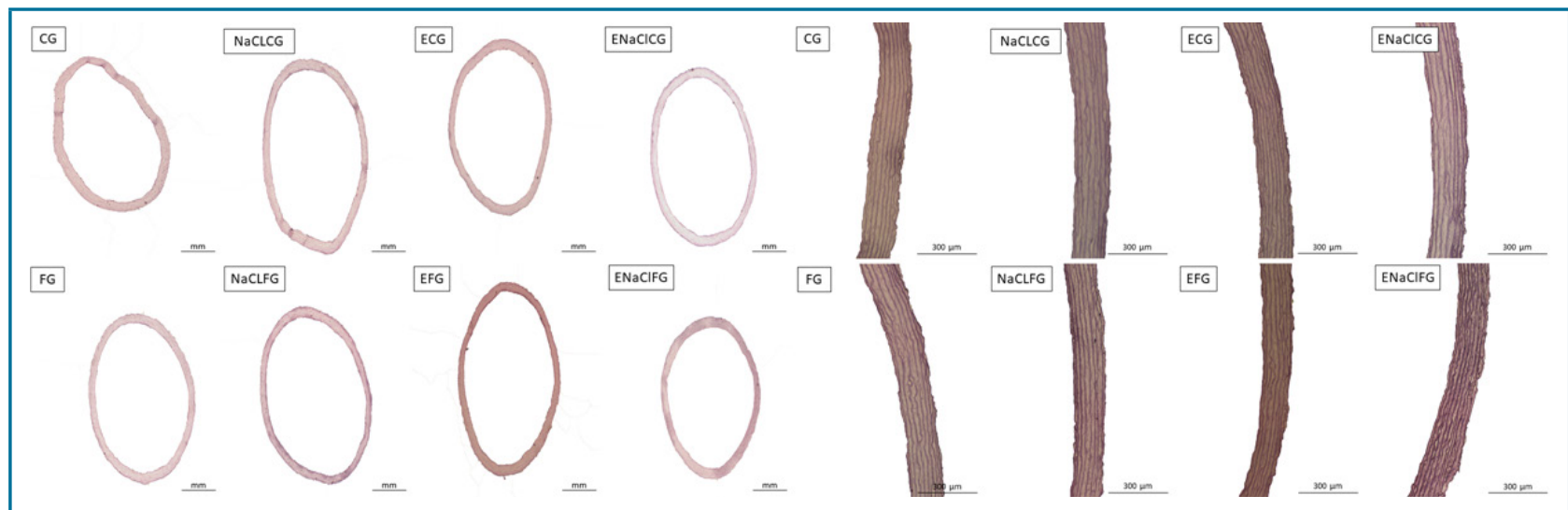

Figure 4 - Microscopic images of the aorta tissue stained with Weigert's Resorcin-Fuchsin in 6- month-old (180 days) male offspring $(4 \mathrm{x}$ and $20 \mathrm{x}$ ). CG: Control group; NaClCG: Sodium Chloride control group; ECG: Exercise training control group; ENaClCG: Sodium Chloride exercise training control group; FG: Flaxseed group; NaClFG: Sodium Chloride flaxseed group; EFG: Exercise training flaxseed group; ENaClFG: Sodium Chloride exercise training flaxseed group.

training of the offspring resulted in structural changes of the aorta of the offspring in adulthood, regardless of sodium intake.

In a review study on the effects of flaxseed flour intake during pregnancy and lactation on the offspring's body mass at 21 days, ${ }^{11}$ it was observed that the consumption of flaxseed flour in a concentration of $25 \%$ ( $25 \mathrm{~g}$ flour $/ 100 \mathrm{~g}$ of feed) in the diet did not lead to changes in the animals' body mass at weaning, showing the same body mass as the animals of control rat dams. ${ }^{21-24}$ In our study, although no statistically difference was found, a trend to lower body mass in animals of rat dams that consumed flaxseed diet during lactation was found. Other studies ${ }^{25-27}$ reported lighter body mass of male offspring of rat dams who consumed flaxseed diet when compared to offspring of rat dams who consumed a control diet. The lower fat mass of these animals is probably the responsible component for the lower body mass at weaning, since animals did not show changes in other compartments of the body. ${ }^{27}$ The flaxseed phytoestrogen, secoisolariciresinol diglucoside (SDG), can be responsible for this effect. The SDG antiobesity effect may be due to the suppression of genes involved in the synthesis of fatty acids and triglycerides, through the sterol regulatory element binding protein-1c (SREBP-1c) activity. It is well known that estrogen directly inhibits fat deposition by reducing lipoprotein lipase (LPL) activity, an enzyme that regulates adipocyte lipid reabsorption; ${ }^{28}$ thus, the lower body mass in the flaxseed group can also be explained, somewhat, by the estrogenic action of the SDG in adipocytes. ${ }^{11,27}$
Flaxseed flour intake by mother during lactation, the practice of regular exercise training after three months of age and consumption of $1 \% \mathrm{NaCl}$ solution did not lead to changes in feed intake during study time and, hence, the offspring's body mass was similar in most groups throughout the study. Only from the 12th week, the ENaClFG had lower body mass compared to some of the groups. Despite not significantly different, feed intake in this group decreased by $9.4 \%$ compared to the other groups, which, in addition to the combination maternal flaxseed intake during lactation, chronic 1\% $\mathrm{NaCl}$ solution intake and exercise training - may have contributed to the lower body mass.

Concerning water and $1 \% \mathrm{NaCl}$ solution intake, the animals given only saline solution drank more fluid than those given only water, resulting in a higher sodium intake in the former groups. Small increases of $1-2 \%$ in the effective osmotic pressure of plasma result in stimulation of thirst in mammals. It has been shown in both human subjects and other mammals, that plasma osmolality is increased experimentally in response to increased concentrations of solutes, such as $\mathrm{NaCl}$, which does not readily pass across cell membranes. Consequently, thirst is stimulated to avoid possible dehydration, ${ }^{29}$ which may have occurred in our animals.

Although salt intake in the diet is recognized as a contributing factor to the pathogenesis of hypertension, recent evidence suggests that salt intake in the diet may increase the risk of adverse cardiovascular events regardless of blood pressure. ${ }^{30,31}$ This is in accordance with our results, showing that the offspring that received 
$1 \% \mathrm{NaCl}$ solution, both of control rat dams and mothers who received the flaxseed diet, showed no increase in blood pressure throughout the study. Similar findings were obtained by offering oral $\mathrm{NaCl}$ at $1 \%{ }^{32}$ or a diet with $1.3 \% \mathrm{NaCl}^{33}{ }^{33}$ wich did not result in an increase in systolic blood pressure in normotensive rats. Few studies have investigated the effects of maternal intake of flaxseed flour during lactation on blood pressure in adult offspring. The intake of a high-fat diet added with flaxseed flour during pregnancy and lactation did not lead to changes in systolic blood pressure in male offspring of diabetic rats at 100 days of life, ${ }^{34}$ corroborating our results; however, another study reported that the intake of flaxseed flour during pregnancy and lactation led to a blood pressure decrease in the offspring of healthy rat dams. ${ }^{35}$ In addition, our study showed that exercise training did not lead to differences in blood pressure between sedentary and trained animals. Studies with sedentary animals and trained animals also presented similar blood pressure levels between groups, ${ }^{36-38}$ yet another study showed that chronic exercise training (treadmill) led to a decrease in blood pressure in normotensive rats. ${ }^{39}$

Several lines of evidence suggest that excessive dietary salt intake $(\mathrm{NaCl})$ negatively affects cardiovascular function, regardless of changes in blood pressure. First, population studies have indicated that normotensive humans with a higher level of salt intake are at increased risk for an adverse cardiovascular event. Second, evidence in humans and animal models indicates that excessive dietary salt intake promotes endothelial and microvascular dysfunction. ${ }^{30}$ Endothelium has multiple and important roles in physiological and pathophysiological events, ${ }^{40}$ and changes in the structure of large arteries, including abnormalities in endothelial function, arterial elasticity, structure and arterial wall thickness, can trigger the onset of cardiovascular disease. ${ }^{41}$ Thereby, assessment of large arteries, such as aorta, of lumen area, elasticity changes and intima-media thickness have become important in the investigation of atherosclerosis, since they are indicators of endothelial damage. ${ }^{42,43}$

In this study, the aorta wall area and the aortic lumen area were similar between groups, showing that the interventions did not affect these results. In relation to flaxseed, a study using a diet with $25 \%$ of flaxseed flour during pregnancy and lactation of diabetic rats showed no difference in the aorta lumen area of male offspring at 100 days of life. ${ }^{13}$ In our study, chronic administration of $1 \% \mathrm{NaCl}$ solution to offspring of mothers who received control diet during lactation led to an increase in aortic intima-media thickness, and to a smaller number of elastic lamellae and, although not significant, the aorta elastin amount was also lower than the control group $(-17,2 \%)$. These results were not found in the offspring of mothers who consumed flaxseed during lactation, once the aortic intima-media thickness of the FG was similar to CG; also, chronic salt overload did not increase aortic intima-media thickness, suggesting a protective effect of flaxseed. Sodium's deleterious effects on endothelial function of offspring of the CG may be associated with the action of reactive oxygen species, such as superoxide, resulting in reduced nitric oxide bioavailability. Cell culture studies support that high sodium exposure stiffens endothelial cells and damages the glycocalyx. ${ }^{2,44}$ Besides that, changes in elastin deposition in the arteries lead to elasticity loss and consequent increased stiffness, promoting aortic remodeling by thickening of the intima-media layer. ${ }^{45}$ Concerning the use of flaxseed during lactation on aortic morphology, different from our results, in a study where flaxseed was given to healthy rats from lactation to adult life, intima-media thickness was smaller than the group that received the control diet. ${ }^{12}$ Also, studies in which flaxseed diet was given to diabetic mothers during pregnancy and lactation reported that male and female offspring as adults showed smaller aortic intima-media thickness than the offspring of healthy mothers. ${ }^{13,14}$

Flaxseed is a rich vegetable source of n-3 fatty acid, which is known for its ability of preventing aortic remodeling due to its capability to be transferred by the placental route and incorporated into the cell membrane modifying its properties. Omega-3 fatty acids are also important anti-inflammatory agents able to decrease endothelial activation and generation of inflammatory cytokines, preventing cardiovascular diseases. ${ }^{11}$

It was observed that exercise training (treadmill), as observed with the chronic use of $\mathrm{NaCl}$, increased aortic intima-media thickness, both in the offspring of control group and in the flaxseed group when compared to their respective sedentary groups. Coura et al., ${ }^{46}$ using swimming as exercise training (5 times/week, 30 minutes/day, for eight weeks), also showed that training increased aortic intima-media thickness of elderly Wistar rats. Despite the increase, Mulvany et al. ${ }^{47}$ reported that resistance arteries suffer an internal eutrophic remodeling, with no changes in the tissue constituent materials, which is noticed in our results related to the number of elastic lamellae and elastin amount that were similar or greater than the respective sedentary group. 


\section{Conclusion}

In summary, despite unaltered blood pressure, chronic salt overload caused adverse effects on the aorta of rats, with decreased aortic elasticity. This was prevented by the consumption of a flaxseed diet during lactation, suggesting a protective effect of flaxseed. Exercise training alone increased aortic intima-media thickness but did not affect its elastic components.

\section{Author Contributions}

Conception and design of the research: Vicente GC, Correia-Santos AM and Boaventura GT. Acquisition of data: Silva-Couto S, Castro CLC, Barreto VLM, Martins JEC and Lenzi Q. Analysis and interpretation of the data: Correia-Santos AM, Vicente GC, Chagas MA and Boaventura GT. Writing of the manuscript: Silva-Couto S, Correia-Santos AM, Vicente GC and Castro CLC. Critical revision of the manuscript for intellectual content: Silva-Coutro S, Correia-Santos AM, Vicente GC, and Boaventura GT.

\section{References}

1. Oliveira MM, Malta DC, Santos MAS, Oliveira TP, Nilson EAF, Claro RM. Self-reported high salt intake in adults: data from the National Health Survey, Brazil, 2013. Epidemiol Serv Saúde. 2015;24(2):249-56.

2. Farquhar WB, Edwards DG, Jurkovitz CT, Weintraub WS. Dietary sodium and health: more than just blood pressure. J Am Coll Cardiol. 2015;65(10):1042-50.

3. Zhu J, Huang T, Lombard JH. Effect of high-salt diet on vascular relaxation and oxidative stress in mesenteric resistance arteries. J Vasc Res. 2007;44(5):382-90.

4. DuPont JJ, Greaney JL, Wenner MM, Lennon-Edwards S, Sanders PW Farguhar WB, et al. High dietary sodium intake impairs endotheliumdependent dilation in healthy salt-resistant humans. J Hypertens. 2013;31(3):530-6.

5. Greaney JL, DuPont JJ, Lennon-Edwards SL, Sanders PW, Edwards DG, Farquhar WB. Dietary sodium loading impairs microvascular function independent of blood pressure in humans: role of oxidative stress. J Physiol. 2012;590(21):5519-28.

6. Imaizumi Y, Eguchi K, Murakami T, Arakawa K, Tsuchihashi T, Kario $\mathrm{K}$. High salt intake is independently associated with hypertensive target organ damage. J Clin Hypertens (Greenwich). 2016;18(4):315-21.

7. Mozaffarian D, Fahimi S, Singh GM, Micha R, Khatibzadeh S, Engell $\mathrm{RE}$, et al. Global sodium consumption and death from cardiovascular causes. N Engl J Med. 2014;371(7):624-34.

8. Coelho CF, Burini RC. Physical activity to prevent and treat noncommunicable chronic diseases and functional disability. Rev Nutr. 2009;22(6):937-46.

9. Rique ABR, Soares EA, Meirelles CM. Nutrition and exercise on cardiovascular disease prevention and control. Rev Bras Med Esporte. 2002;8(6):244-54

10. Corrêa LBNS, Cardozo LFM, Ribeiro ICA, Boaventura GT, Chagas MA. Influence of prolonged flaxseed ( Linum usitatissimum ) consumption

\section{Potential Conflict of Interest}

No potential conflict of interest relevant to this article was reported.

\section{Sources of Funding}

This study was partially funded by Coordenação de Aperfeiçoamento de Pessoal de Nível Superior - Brasil (Coordination for the Improvement of Higher Education Personnel, CAPES) (Finance Code 001).

\section{Study Association}

This article is part of the thesis of master submitted by Simoni Silva-Couto, from Universidade Federal Fluminense.

\section{Ethics Approval and Consent to Participate}

This study was approved by the Ethics Committee on Animal Experiments of the Universidade Federal Fluminense under the protocol number 882/2016.

over epididymis and testicle histoarchitecture of Wistar rats. Pesq Vet Bras. 2017;37(6):650-6.

11. Correia-Santos AM, Vicente GC, Boaventura GT. Functional implications of maternal intake of flaxseed and its by-products during pregnancy and lactation on offspring: Review of animal studies. Nutr Food Sci. 2017;47(4):477-89.

12. Cardozo LFMF, Vicente GC, Brant LHC, Mafra D, Chagas MA Boaventura GT. Prolonged flaxseed flour intake decreased the thickness of the aorta and modulates some modifiable risk factors related to cardiovascular disease in rats. Nutr Hosp. 2014;29(2):376-81.

13. Vicente GC, Correia-Santos AM, Suzuki A, Velarde LGC, Chagas MA Boaventura GT. Maternal exposure to diets containing flaxseed flour or flaxseed oil during pregnancy and lactation protects the aortic remodeling in adult male offspring of diabetic rat dams. J Sci Food Agric. 2015;95(14):2973-80

14. Vicente GC, Correia-Santos AM, Suzuki A, Chagas MA, Boaventura GT. Maternal use of a diet rich omega-3 from flaxseed improves aortic remodeling but not the biochemical parameters of female offspring of diabetic rats. Eur J Lipid Sci Technol. 2014;117(3):292-9.

15. Kajla P, Sharma A, Sood DR. Flaxseed-a potential functional food source. J Food Sci Technol. 2015;52(4):1857-71.

16. Khalesi S, Irwin C, Schubert M. Flaxseed consumption may reduce blood pressure: a systematic review and meta-analysis of controlled trials. J Nutr. 2015;145(4):758-65.

17. Reeves PG, Nielsen FH, Fahey GC Jr. AIN-93 purified diets for laboratory rodents: final report of the American Institute of Nutrition ad hoc writing committee on the reformulation of the AIN-76A rodent diet. J Nutr. 1993;123(11):1939-51.

18. Damy SB, Camargo RS, Chammas R, Figueiredo LFP. The fundamentals of experiments with animals - applications in experimental surgery. Rev Assoc Med Bras. 2010;56(1):103-11. 
19. Felix JVC, Michelini LC. Training-induced pressure fall in spontaneously hypertensive rats is associated with reduced angiotensinogen mRNA expression within the nucleus tractus solitarii. Hypertens. 2007;50(4):780-5

20. Pereira LM, Vianna GM, Mandarim-de-Lacerda CA. Morphology and stereology of the myocardium in hypertensive rats. Correlation with the time of nitric oxide synthesis inhibition. Arq Bras Cardiol. 1998;70(6):397-402

21. Brant LHC, Cardozo LFMF, Velarde LGC, Boaventura GT. Impact of flaxseed intake upon metabolic syndrome indicators in female Wistar rats. Acta Cir Bras. 2012;27(8):537-43.

22. Costa CAS, Silva PCA, Ribeiro DC, Pereira ADD, Santos ADSD, Maia LDA, et al. Body adiposity and bone parameters of male rats from mothers fed diet containing flaxseed flour during lactation. J Dev Orig Health Dis. 2016;7(3):314-9.

23. Soares LL, Cardozo LFMF, Troina AA, Ramos CFR, Guzmán-Silva MA, Boaventura GT. Influence of flaxseed during lactation on the reproductive system of female Wistar rats. Nutr Hosp. 2010;25(3):437-42.

24. Leite CDFC, Vicente GC, Suzuki A, Pereira AAP, Boaventura GT, Santos $\mathrm{RM}$, et al. Effects of flaxseed on rat milk creamatocrit and its contribution to offspring body growth. J Pediatr (Rio J). 2012;88(1):74-8.

25. Cardozo LFMF, Soares LL, Chagas MA, Boaventura GT. Maternal consumption of flaxseed during lactation affects weight and hemoglobin level of offspring in rats. J Pediatr (Rio J). 2010;86(2):126-30.

26. Fernandes FS, Souza AS, Carmo MGT, Boaventura GT. Maternal intake of flaxseed-based diet (Linum usitatissimum) on hippocampus fatty acid profile: implications for growth, locomotor activity and spatial memory. Nutrition. 2011;27(10):1040-7.

27. Troina AA, Figueiredo MS, Moura EG, Boaventura GT, Soares LL, Cardozo LFMF, et al. Maternal flaxseed diet during lactation alters milk composition and programs the offspring body composition, lipid profile and sexual function. Food Chem Toxicol. 2010;48(2):697-703.

28. Hamosh M, Hamosh P. The effect of estrogen on the lipoprotein lipase activity of rat adipose tissue. J Clin Invest. 1975;55(5):1132-5.

29. McKinley MJ, Johnson AK. The Physiological regulation of thirst and fluid intake. News Physiol Sci. 2004 Feb;19(1):1-6.

30. Simmonds SS, Lay J, Stocker SD. Dietary salt intake exaggerates sympathetic reflexes and increases blood pressure variability in normotensive rats. Hypertension. 2014;64(3):583-9.

31. Washino S, Hosohata K, Jin D, Takai S, Miyagawa T. Early urinary biomarkers of renal tubular damage by a high-salt intake independent of blood pressure in normotensive rats. Clin Exp Pharmacol Physiol. 2018;45(3):261-8

32. Oliveira EM, Krieger JE. Chronic $\beta$-adrenoceptor stimulation and cardiac hypertrophy with no induction of circulating renin. Eur J Pharmacol. 2005;520(1):135-41.

33. Ferreira DN, Katayama IA, Oliveira IB, Rosa KT, Furukawa LNS, Coelho MS, et al. Salt-induced cardiac hypertrophy and interstitial fibrosis are due to a blood pressure-independent mechanism in Wistar rats. J Nutr. 2010;140(10):1742-51.
34. Vicente GC, Correia-Santos AM, Suzuki A, Anjos JS, Velarde LGS, Chagas MA, et al. Perinatal consumption of flaxseed oil and flaxseed flour has beneficial effects on cardiac fibrosis of male offspring from rat dams with experimental diabetes. Food Res Int. 2016 May;83:162-8.

35. Meneses JA, Trugilho LA, Lima SA, Freitas ACF, Melo HS, Ferreira MR, et al. The influence of a diet based on flaxseed, an omega-3 source, during different developmental periods, on the blood pressure of rats submitted to stress. J Matern Fetal Neonatal Med. 2019;32(9):1516-22.

36. Brum PC, Silva GJJD, Moreira ED, Ida F, Negrão CE, Krieger EM. Exercise training increases baroreceptor gain sensitivity in normal and hypertensive rats. Hypertension. 2000;36(6):1018-22.

37. Kuru O, Şentürk Ü, Demir N, Yeşilkaya A, Ergüler G, Erkılıç M. Effect of exercise on blood pressure in rats with chronic NOS inhibition. Eur J Appl Physiol. 2002;87(2):134-40.

38. Niederhoffer N, Kieffer P, Desplanches D, Lartaud-Idjouadiene I, Sornay $\mathrm{MH}$, Atkinson J. Physical exercise, aortic blood pressure, and aortic wall elasticity and composition in rats. Hypertension. 2000;35(4):919-24.

39. Hsu YC, Chen HI, Kuo YM, Yu L, Huang TY, Chen SJ, et al. Chronic treadmill running in normotensive rats resets the resting blood pressure to lower levels by upregulating the hypothalamic GABAergic system. J Hypertens. 2011;29(12):2339-48.

40. Carvalho MHC, Nigro D, Lemos VS, Tostes RCA, Fortes ZB. Arterial hypertension: endothelium and multiples functions. Rev Bras Hipertens. 2001;8(1):76-88

41. Pizzi O, Brandão AA, Magalhães MEC, Pozzan R, Brandão AP. Pulse wave velocity - methodology and prognostic implications in hypertension. Rev Bras Hipertens. 2006;13(1):59-62.

42. McCloskey K, Vuillermin P, Ponsonby AL, Cheung M, Skilton MR, Burgner D. Aortic intima-media thickness measured by trans-abdominal ultrasound as an early life marker of subclinical atherosclerosis. Acta Paediatr. 2014;103(2):124-30.

43. Visentin S, Grumolato F, Nardelli GB, Di Camillo B, Grisan E, Cosmi E. Early origins of adult disease: low birth weight and vascular remodeling. Atherosclerosis. 2014;237(2):391-9.

44. Oberleithner H, Peters W, Kusche-Vihrog K, Korte S, Schillers H, Kliche $\mathrm{K}$, et al. Salt overload damages the glycocalyx sodium barrier of vascular endothelium. Pflugers Arch. 2011;462(4):519-28

45. Kornet L, Lambregts J, Hoeks AP, Reneman RS. Differences in nearwall shear rate in the carotid artery within subjects are associated with different intima-media thicknesses. Arterioscler Thromb Vasc Biol. 1998;18(12):1877-84.

46. Coura MAS, Pacheco ME, Simões HG, Moraes JFVN, Campbell CSG. Morphoquantitative study of the aorta's wall in aerobically trained elderly wistar rats. Motricidade. 2012;8(4):71-9.

47. Mulvany MJ, Baumbach GL, Aalkjaer C, Heagerty AM, Korsgaard N, Schiffrin EL, et al. Vascular remodeling. Hypertension. 1996;28(3):505-6. 